\title{
Primary hyperparathyroidism presenting as unilateral visual loss
}

\author{
D. Chappel and K. Farrington \\ King George Hospital, Eastern Avenue, Ilford, Essex 1G2 7RL, UK
}

\begin{abstract}
Summary: A 58 year old woman presented with unilateral visual loss due to ischaemic optic neuropathy. Investigations revealed severe hypercalcaemia due to hyperparathyroidism. Excision of a large parathyroid adenoma restored normocalcaemia. Visual acuity was unchanged. There was no evidence of any condition known to be associated with ischaemic optic neuropathy, or of any abnormal clotting tendency. The association between primary hyperparathyroidism and ischaemic optic neuropathy may be causal and related to vascular damage mediated by hypercalcaemia.
\end{abstract}

\section{Introduction}

Primary hyperparathyroidism has a number of possible ocular effects. Calcification of ocular structures commonly manifests as band keratopathy or conjunctival calcification. More unusually exophthalmos due to an orbital brown tumour has been reported. ${ }^{1}$ We report a case of primary hyperparathyroidism with severe hypercalcaemia which presented as visual loss due to ischaemic optic neuropathy, an association which we believe has not been reported previously.

\section{Case report}

A 58 year old woman presented with a 5-month history of deteriorating vision. She was referred by her general practitioner to an ophthalmologist. Vision in the right eye was reduced to counting fingers. There was a dense central scotoma. The optic disc was swollen, especially in the upper nasal quadrant. The superior and inferior nasal arteries were attenuated. Visual evoked potentials were absent. The left eye was normal in all respects. Ischaemic optic neuropathy was diagnosed.

Further medical assessment revealed no history of angina or intermittent claudication. Blood pressure was $180 / 100 \mathrm{mmHg}$. There were no clinical signs of dehydration. All peripheral pulses were palpable. The major abnormality on investigation was a high serum calcium of $3.66 \mathrm{mmol} / \mathrm{l}$ (normal range 2.12-2.62). Other investigations included serum phosphate $0.59 \mathrm{mmol} / 1(0.80-1.60)$, alkaline phosphatase $446 \mathrm{U} / 1(85-270)$, and serum creatinine $120 \mu \mathrm{mol} / 1$ (60-120). Plasma electro-

Correspondence: K. Farrington, M.D., M.R.C.P. Accepted: 26 November 1990 lytes and glucose, haemoglobin, packed cell volume, platelet count, ESR, prothrombin time, kaolin cephalin clotting time, thrombin time, antithrombin III levels, protein S and C levels, serum protein electrophoresis, serum angiotensin converting enzyme, chest X-ray, bone scan and lumbar puncture, were all normal. Serological tests for syphilis and anticardiolipin antibody were negative. A steroid suppression test showed no significant fall in serum calcium. Amino terminal parathyroid hormone level was $820 \mathrm{pg} / \mathrm{ml}$ (normal $<120 \mathrm{pg} / \mathrm{ml}$ ). A technetium-thallium subtraction scan showed increased uptake at the left lower border of the thyroid gland.

At neck exploration, a large parathyroid adenoma $(2.5 \times 3.5 \times 2 \mathrm{~cm})$ was removed from the site indicated by the scan. Histology confirmed the diagnosis. The serum calcium fell to $2.24 \mathrm{mmol} / \mathrm{l}$ on the 4th post-operative day. Subsequently the serum calcium was maintained within the normal range with reducing doses of 1 alpha-hydroxycholecalciferol and calcium supplements. Eighteen months post-parathyroidectomy, the serum calcium and alkaline phosphatase levels were normal on no treatment, the blood pressure had fallen to $155 / 85 \mathrm{mmHg}$, and examination of the right eye revealed optic atrophy and unchanged acuity.

\section{Discussion}

Eye complications of primary hyperparathyroidism are common but ischaemic optic neuropathy has not been reported previously. Papilloedema has been observed in a patient with hypercalcaemia and hyperparathyroidism associated with renal failure, though visual acuity was normal. $^{2}$ 
If the association we are reporting was causal, there are several possible mechanisms. Severe hypercalcaemia often causes dehydration which predisposes to thrombosis, and multiple cerebral microthrombi have been reported in fatal cases. ${ }^{3}$ Hypercalcaemia may cause vascular calcification, though this is usually medial and by itself is rarely a cause of major vascular occlusion. Cerebral vasospasm has been documented in association with hypercalcaemia, and attributed to the effects of increased intracellular free calcium levels on actinmyosin coupling in cerebrovascular smooth muscle

\section{References}

1. Block, M.B., Johnson, H. \& Kartub, M.G. Unilateral exophthalmos: an unusual presentation of hyperparathyroidism. Ariz Med 1978, 12, 785-786.

2. Murphy, K.J. Papilloedema due to hyperparathyroidism. Br J Ophthalmol 1974, 58: 694-697.

3. Bauermeister, D.E., Jennings, E.R., Cruse, D.R. \& Demott Sedgewick, V. Hypercalcaemia with seizures. A clinical paradox. JAMA 1967, 201: 132-134. cells. ${ }^{4}$ There is a recognized association between hypercalcaemia and hypertension, a potent cause of vascular damage, and in our patient the initially elevated blood pressure improved after parathyroidectomy. Finally, there is some evidence that parathyroid hormone may have toxic effects on many organs, including neural tissue, which are independent of raised serum calcium levels. ${ }^{5}$ It is our contention that one or more of these mechanisms may have contributed to the ischaemic damage to the optic nerve sustained by our patient.

4. Walker, G.L., Williamson, P.M., Ravich, R.B.M. \& Roche, J. Hypercalcaemia associated with cerebral vasospasm causing infarction. J Neurol Neurosurg Psychiatry 1980, 43, 464-467.

5. Massry, S.G. Neurotoxicity of parathyroid hormone in uraemia. Kidney Int 1985, 28(Suppl 17), S5-S11. 